\title{
ANALYTICAL SOLUTION TO THE PROBLEM OF CONVECTIVE HEAT TRANSFER IN A POROUS RECTANGULAR CHANNEL FOR THERMAL BOUNDARY CONDITIONS OF THE SECOND GENUS
}

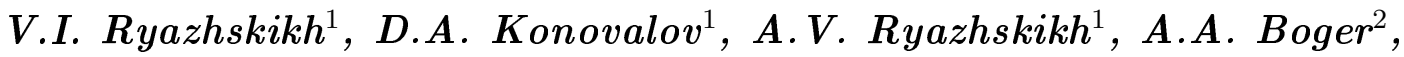 \\ S.V. Dakhin ${ }^{1}$ \\ ${ }^{1}$ Voronezh State Technical University, Voronezh, Russian Federation \\ ${ }^{2}$ Military Educational Scientific Center of the Military - Air Forces "Military Air \\ Academy named after Professor N.E. Zhukovsky and Yu.A. Gagarin", \\ Voronezh, Russian Federation \\ E-mail: ryazhskih_vi@mail.ru,dmikonovalov@yandex.ru,ryazhskihav@bk.ru, \\ a-boger@yandex.ru, secretary-d21203705@yandex.ru
}

\begin{abstract}
In the three-dimensional statement, we consider the Brinkman equation together with the equation of heterogeneous heat transfer for an unidirectional flow of the Newtonian fluid under laminar regime through horizontal porous channel having a constant rectangular cross-section with known thermal flows at the boundary and small values of the Darcy numbers. Due to the linearity of the formulated system of model equations, we obtain analytical solution of the system using the Laplace and Fourier integral transformation. The obtained solution allows to estimate the length of the input hydrodynamic section, the coefficient of hydraulic resistance, and the local Nusselt numbers. The results obtained for the hydrodynamic subproblem with a large porosity and thermal subproblem with a stationary temperature field agree with the classical data.

Keywords: porous medium; convective heat transfer; rectangular channel; coefficient of hydraulic resistance; initial hydrodynamic section.
\end{abstract}

\section{Introduction}

The most effective active method to intensify a heat transfer in heat exchangers of different energy systems is the use of porous mediums as fillers of the channels through which the fluid (gaseous) heat carriers with simultaneous transfer of heat are transfered [1]. The role of this intensification method significantly increases, if powerful heat flows are removed from the compact heat-stressed surfaces. For example, in electronic miniature devices the electromagnetic energy dissipates into thermal energy [2]. In order to choose the constructions of compact heat exchangers correctly, the analysis of transfer phenomena in the exchangers requires an estimation of the heat transfer in the three-dimensional statement, taking into account the hydrodynamic structure of flow in the input section of the porous channel. Therefore, the identification of hydrodynamic characteristics of porous heat exchangers in the form of regular parallelepipeds is necessary [4]. Up the present, the heat transfer in the porous channel having rectangular cross section was not considered [5]. The papers $[6,7]$ are among the first publications, where the problem was solved on the basis of the stationary Darcy - Brinkman equation in the Stokes approximation and the one-temperature model of heat transfer with different boundary conditions for the constant axial heat flow. The experimental studies show that we should abandon hypothesis about local thermal equilibrium between the porous filler and fluid (gaseous) heat carrier [8]. Therefore, under the same assumptions as in $[6,7]$ and within the framework of linear 
statement of the problem, the possibility to obtain a solution using the two-temperature model of the heat transfer is shown [9]. However, according to [10], if we do not accept the above simplifications, then the analytical solution is difficult to be obtained in this statement and it is necessary to use the numerical integration. For low porosity, the velocity profile of the heat carrier is determined almost instantly in the input section of the porous channel [11]. However, the appearence of such a filler as metal foam with a high degree of porosity [12] additionally requires to estimate the possible influence of the hydrodynamic initial section on the heat transfer in the porous channel.

In this connection, we analytically analyze the heat transfer of the mass in the rectangular porous channel under the laminar flow of the heat carrier within the framework of the Brinkman approximation of the Darcy - Brinkman - Forchheimer equation and the two-temperature model of the heat exchange in a wide range of the main parameters variation. Also, we determine the conditions under which the influence of the length of the hydrodynamic initial section on the heat transfer can be neglected.

\section{Basic Equations and Assumptions}

According to [13], we represent the physical model of a porous medium in the form of a dense non deformable packing of spheres. The emptiness of the packing is connected and filled with moving Newtonian fluid without phase transitions in Laminar regime under the action of an applied pressure gradient.

The hydrodynamic subproblem is described within the framework of the Darcy Brinkman - Forchheimer phenomenological model by the $\mathrm{Xu}$ - Cheng equations [14], obtained by the method of volume averaging:

$$
\begin{gathered}
\nabla \cdot \bar{V}=0, \\
\frac{\rho_{f}}{\varepsilon}\left[\frac{\partial \bar{V}}{\partial \tau}+\frac{(\bar{V} \cdot \nabla) \bar{V}}{\varepsilon}\right]=\rho_{f} \bar{g}-\nabla p+\mu_{f} \nabla^{2} \bar{V}-\left[\mu_{f} \frac{\bar{V}}{K}+\rho_{f} \frac{b \bar{V}|\bar{V}|}{\sqrt{K}}\right],
\end{gathered}
$$

here $\tau$ is time; $\rho_{f}, \mu_{f}$ are density and dynamic viscosity of the fluid; $\varepsilon$ is porosity; $\bar{V}$ is vector of the fluid velocity; $\bar{g}$ is vector of the free fall acceleration; $p$ is pressure. The permeability of a porous medium is determined from the modified Kozeny - Karman equation [15]

the Forchheimer friction factor is

$$
K=\varepsilon^{2} d_{p}^{2} /[150-(1-\varepsilon)],
$$

$$
b \approx 0,00117 d_{p} /(1-\varepsilon),
$$

where $d_{p}$ is a number-average diameter of spherical particles in the porous layer.

The temperature fields are determined from the equations of the Schumann twotemperature model [16]:

for a fluid

$$
\varepsilon\left(\rho c_{p}\right)_{f} \frac{\partial t_{f}}{\partial \tau}+\varepsilon\left(\rho c_{p}\right)_{f} \bar{V} \cdot \nabla t_{f}=\nabla \cdot\left(\lambda_{e}^{f} \bullet \nabla t_{f}\right) \pm \alpha_{s f} a_{s f}\left(t_{s}-t_{f}\right),
$$

for the skeleton of a porous medium

$$
(1-\varepsilon)\left(\rho c_{p}\right)_{s} \frac{\partial t_{s}}{\partial \tau}=\nabla \cdot\left(\lambda_{e}^{s} \bullet \nabla t_{s}\right) \mp \alpha_{s f} a_{s f}\left(t_{s}-t_{f}\right)
$$


where $\lambda_{e}^{f}, \lambda_{e}^{s}$ are tensors of the effective heat conductivity coefficients of the fluid and the material of a porous body skeleton, respectively; $t_{f}, t_{s}$ are temperatures of the fluid and the skeleton of a porous body, respectively; $\alpha_{s f}$ is a coefficient of the heat transfer between the liquid phase and the skeleton of a porous body; $a_{s f}$ is characteristic area of the wetted surface in a porous body; $\rho_{s}, c_{p s}$ is density and mass heat capacity of the skeleton of the porous body; $c_{p f}$ is mass heat capacity of the liquid.

We assume that the thermophysical parameters in (1) - (4) are homogeneous in spatial coordinates and do not depend on temperature. In this case, according to [17],

$$
\begin{gathered}
a_{s f}=6(1-\varepsilon) / d_{p}, \quad \alpha_{s f}=\lambda_{f}\left[2+1,1 \operatorname{Pr}^{0^{1 / 3}}\left(\rho_{f}|\bar{V}| d_{p} / \mu_{f}\right)^{0,6}\right] / d_{p}, \\
\lambda_{e}^{f}=\left[\varepsilon+(0,1 \div 0,5) \operatorname{Pr}^{0}\left(\frac{\rho_{f}|\bar{V}| d_{p}}{\mu_{f}}\right)\right] \lambda_{f}, \quad \lambda_{e}^{s}=(1-\varepsilon) \lambda_{s},
\end{gathered}
$$

where $\operatorname{Pr}^{0}=\mu_{f} c_{p f} / \lambda_{f}, \lambda_{f}, \lambda_{s}$ is heat conductivity of the fluid and the skeleton of a porous body, respectively.

The phenomenological nature of the model in a porous body allows to formulate the boundary conditions within the framework of the classical analysis of the problems of heat and mass transfer for homogeneous media [18].

Despite the simplified formulation of the problem, the integration of the system (1) (4) with heat boundary conditions of the first or second genus on the side of the cooled surface causes the same difficulties as the joint integration of the Navier - Stokes and the heat transfer equations [19]. An overview of numerical and approximate analytical methods for solving the system (1) - (4) is given in [20].

\section{Mathematical Model}

As opposed to the constructive flat heat exchangers for which the analysis of hydrodynamics and heat exchange in 2-D format can be applied, for heat exchangers having commensurate ratio of the width and height of the flow section, it is necessary to solve the problem in a three-dimensional statement.

Suppose that a laminar flow of a heat carrier (a Newtonian incompressible medium) having temperature $t_{0}$ with velocity $u_{0}$ is given to the input of a porous heat exchanger having length $l$ with a constant cross section of height $h_{1}$ and width $h_{2}$ (Fig. 1 ). We assume

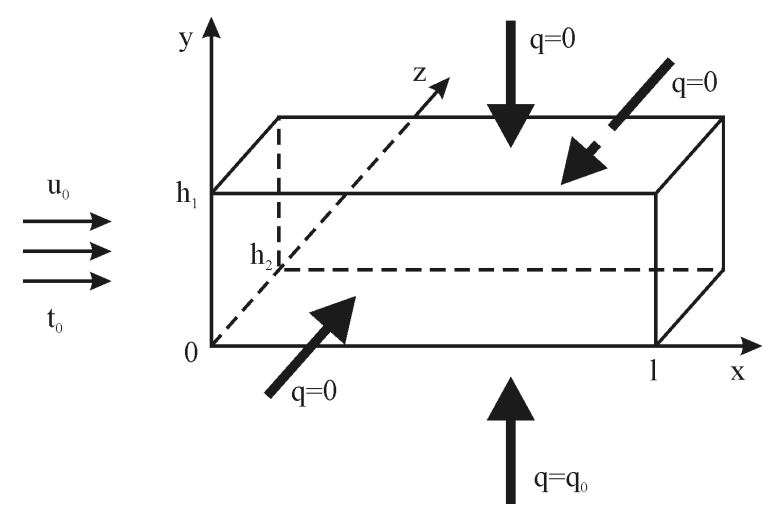

Fig. 1. 3-D analytical model of the heat exchanger 
that the body of the heat exchanger is impenetrable for the heat carrier, the lateral and upper surfaces of the heat carrier are heat insulated, and the heat flow $q_{0}$ is given in the lower surface. According to the considered analytical model, the equation (1) - (4) in the dimensionless form is the following:

$$
\begin{aligned}
& \frac{\partial U}{\partial x}+\frac{\partial V}{\partial Y}+\frac{\partial W}{\partial Z}=0 \\
& \frac{\partial U}{\partial \Theta}+U \frac{\partial U}{\partial X}+V \frac{\partial U}{\partial Y}+W \frac{\partial U}{\partial Z}=-\frac{\partial P}{\partial X}++\frac{1}{\operatorname{Re}}\left(\frac{\partial^{2} U}{\partial X^{2}}+\frac{\partial^{2} U}{\partial Y^{2}}+\frac{\partial^{2} U}{\partial Z^{2}}\right)- \\
& -\left(\frac{1}{\mathrm{Re} \cdot \mathrm{Da}}+\frac{B}{\sqrt{\mathrm{Da}}} \sqrt{U^{2}+V^{2}+W^{2}}\right) U \\
& \frac{\partial V}{\partial \Theta}+U \frac{\partial V}{\partial X}+V \frac{\partial V}{\partial Y}+W \frac{\partial V}{\partial Z}=-\frac{\partial P}{\partial Y}+\frac{1}{\operatorname{Re}}\left(\frac{\partial^{2} W}{\partial X^{2}}+\frac{\partial^{2} W}{\partial Y^{2}}+\frac{\partial^{2} W}{\partial Z^{2}}\right)- \\
& -\left(\frac{1}{\mathrm{Re} \cdot \mathrm{Da}}+\frac{B}{\sqrt{\mathrm{Da}}} \sqrt{U^{2}+V^{2}+W^{2}}\right) V \\
& \frac{\partial W}{\partial \Theta}+U \frac{\partial W}{\partial X}+V \frac{\partial W}{\partial Y}+W \frac{\partial W}{\partial Z}=-\frac{\partial P}{\partial Z}+\frac{1}{\operatorname{Re}}\left(\frac{\partial^{2} W}{\partial X^{2}}+\frac{\partial^{2} W}{\partial Y^{2}}+\frac{\partial^{2} W}{\partial Z^{2}}\right)- \\
& -\left(\frac{1}{\mathrm{Re} \cdot \mathrm{Da}}+\frac{B}{\sqrt{\mathrm{Da}}} \sqrt{U^{2}+V^{2}+W^{2}}\right) W \\
& \frac{1}{\varepsilon} \frac{\partial T_{f}}{\partial \Theta}+U \frac{\partial T_{f}}{\partial X}+V \frac{\partial T_{f}}{\partial Y}+W \frac{\partial T_{f}}{\partial Z}=\frac{1}{\operatorname{Re} \cdot \operatorname{Pr}}\left(\frac{\partial^{2} T_{f}}{\partial X^{2}}+\frac{\partial^{2} T_{f}}{\partial Y^{2}}+\frac{\partial^{2} T_{f}}{\partial Z^{2}}\right)+ \\
& +\frac{\mathrm{Nu}_{p} \operatorname{Re}}{\operatorname{Pr} \cdot \operatorname{Re}_{p}^{2}}\left(\Lambda T_{s}-T_{f}\right), \\
& (1-\varepsilon) \operatorname{Lu} \cdot \operatorname{Pr} \cdot \operatorname{Re} \frac{\partial T_{s}}{\partial \Theta}=\frac{\partial^{2} T_{s}}{\partial X^{2}}+\frac{\partial^{2} T_{s}}{\partial Y^{2}}+\frac{\partial^{2} T_{s}}{\partial Z^{2}}- \\
& -\mathrm{Nu}_{p}\left(\frac{\mathrm{Re}}{\operatorname{Re}_{p}}\right)^{2}\left(\Lambda T_{s}-T_{f}\right),
\end{aligned}
$$

where $\Theta=u_{0} \tau /\left(\varepsilon d_{h}\right), X=x / d_{h}, Y=y / d_{h}, Z=z / d_{h}, \quad U=u / u_{0}$, $V=v / u_{0}, W=\omega / u_{0}, u, v, \omega$ are components of the fluid velocity vector; $d_{h}=$ $2 h_{1} h_{2} /\left(h_{1}+h_{2}\right), T_{f}=\lambda_{e}^{f}\left(t_{f}-t_{0}\right) /\left(q_{0} d_{h}\right), T_{s}=\lambda_{s}^{s}\left(t_{s}-t_{0}\right) /\left(q_{0} d_{h}\right), P=\varepsilon^{2} p /\left(\rho_{f} u_{0}^{2}\right)$, $B=\varepsilon^{2} b$ is the dimensionless Forchheimer parameter; Re $=\rho_{f} u_{0} d_{h} /\left(\mu_{f} \varepsilon^{2}\right)$ is the Reynolds number; $\operatorname{Re}_{p}=\rho_{f} u_{0} d_{p} /\left[6(1-\varepsilon) \mu_{f}\right]$ is the local Reynolds number; $\operatorname{Pr}=$ $\varepsilon\left(\rho c_{p}\right)_{f} \mu_{f} /\left(\lambda_{e}^{f} \rho_{f}\right)$ is the Prandtl number; $\mathrm{Nu}_{p}=\alpha_{s f} d_{p} / \lambda_{e}^{f}$ is the local Nusselt number; $\mathrm{Lu}=\left[\lambda_{e}^{f} /\left(\rho c_{p}\right)_{f}\right] /\left[\lambda_{e}^{s} /\left(\rho c_{p}\right)_{s}\right]$ is the modified Lykov number; Da $=K / d_{h}^{2}$ is the Darcy number; $\Lambda=\lambda_{e}^{f} / \lambda_{e}^{s}$. The system (5) - (10) provides the possibility first to analyze the hydrodynamic subproblem and then the heat subproblem.

Laminar flow of the heat-carrier allows to accept the hypothesis that the flow in a porous heat exchanger is unidirectional, i.e. $(V=W \equiv 0)$. Let us take into account the small value of the inertial effects under the decreasing pressure [21] and boundary layer linearization [22], as well as the relation $\Theta=X / \varepsilon$. Therefore, the hydrodynamic subproblem $(5)-(8)$ is reduced to the initial-boundary value problem

$$
\frac{\partial U}{\partial X}=-\frac{1}{\varepsilon} \frac{d P}{d X}+\frac{1}{\varepsilon \operatorname{Re}}\left(\frac{\partial^{2} U}{\partial Y^{2}}+\frac{\partial^{2} U}{\partial Z^{2}}\right)-\frac{U}{\varepsilon \cdot \operatorname{Re} \cdot \mathrm{Da}},
$$




$$
\begin{gathered}
U(0, X, Z)=1, \\
U(X, 0, Z)=U(X, Y, 0)=U\left(X, H_{1}, Z\right)=U\left(X, Y, H_{2}\right)=0,
\end{gathered}
$$

where $H_{1}=(1+\eta) / 2, H_{2}=\left(1+\eta^{-1}\right) / 2, \eta=h_{1} / h_{2}$ are such that $d P / d X$ is determined by the condition that the flow of fluid through the cross section of the porous heat exchanger remains

$$
\frac{1}{H_{1} \cdot H_{2}} \int_{0}^{H_{1}} \int_{0}^{H_{2}} U(\infty, Y, Z) d Y d Z=1 .
$$

Consider the heat subproblem for the stationary heat transfer regime in a porous heat exchanger assuming that $\partial^{2} T_{f, s} / \partial X^{2} \ll\left(\partial^{2} T_{f, s} / \partial Y^{2} \& \partial^{2} T_{f, s} / \partial Z^{2}\right)$ under keeping the condition $d_{h} \ll l[3]$

$$
\begin{gathered}
U \frac{\partial T_{f}}{\partial X}=\frac{1}{\operatorname{Re} \cdot \operatorname{Pr}}\left(\frac{\partial^{2} T_{f}}{\partial Y^{2}}+\frac{\partial^{2} T_{f}}{\partial Z^{2}}\right)+\frac{\mathrm{Nu}_{p} \cdot \operatorname{Re}}{\operatorname{Pr} \cdot \operatorname{Re}_{p}^{2}}\left(\Lambda T_{s}-T_{f}\right) \\
\frac{\partial^{2} T_{s}}{\partial Y^{2}}+\frac{\partial^{2} T_{s}}{\partial Z^{2}}-\operatorname{Nu}_{p}\left(\frac{\operatorname{Re}}{\operatorname{Re}_{p}}\right)^{2}\left(\Lambda T_{s}-T_{f}\right)=0
\end{gathered}
$$

with the boundary conditions

$$
\begin{gathered}
T_{f}(0, Y, Z)=0 \\
\frac{\partial T_{f, s}(X, 0, Z)}{\partial Y}=-1, \\
\frac{\partial T_{f, s}\left(X, H_{1}, Z\right)}{\partial Y}=\frac{\partial T_{f, s}(X, Y, 0)}{\partial Z}=\frac{\partial T_{f, s}\left(X, Y, H_{2}\right)}{\partial Z}=0 .
\end{gathered}
$$

\section{The Hydrodynamic Subproblem}

The system (11) - (13) is linear. Therefore, in order to solve the system we can use the Laplace one-side integral transformation [23] with respect to the variable $X$ and the finite integral sinus-transformation [24] with respect to the variables $X$ and $Z$. As a result,

$$
\begin{gathered}
U(X, Y, Z)=\frac{4}{H_{1} H_{2}} \sum_{m=1}^{\infty} \sum_{n=1}^{\infty}\left(\lambda_{m} \mu_{n}\right)^{-1}\left[1-(-1)^{m}\right]\left[1-(-1)^{n}\right] \times \\
\times\left[\left(1+\frac{C}{a_{m n}}\right) \exp \left(a_{m n} X\right)-\frac{C}{a_{m n}}\right] \sin \left(\lambda_{m} Y\right) \sin \left(\mu_{n} Z\right),
\end{gathered}
$$

where $\lambda_{m}=m \pi / H_{1}, \quad \mu_{n}=n \pi / H_{2}, \quad a_{m n}=-\left(\lambda_{m}^{2}+\mu_{n}^{2}+\mathrm{Da}^{-1}\right) /(\varepsilon \mathrm{Re})$, $C=-\varepsilon^{-1} d P / d X$.

The parameter $C$ is found from the condition (14)

$$
C=\left\{-\frac{4}{H_{1} H_{2}} \sum_{m=1}^{\infty} \sum_{n=1}^{\infty}\left(\lambda_{m} \mu_{n}\right)^{-2}\left[1-(-1)^{m}\right]^{2} \cdot\left[1-(-1)^{n}\right]^{2} / a_{m n}\right\}^{-1}
$$

which allows to determine the coefficient of hydraulic resistance according to Fanning [25]

$$
\xi=2 \xi^{-1} C
$$


The length of the hydrodynamic initial section is calculated for the quasiregular regime [22] $(m=n=1)$ by the relation

$$
1-\frac{U\left(X, H_{1} / 2, H_{2} / 2\right)}{U\left(\infty, H_{1} / 2, H_{2} / 2\right)}=\gamma
$$

(the relative deviation $\gamma$ is usually taken to be 0,02 ), therefore

$$
X=-\frac{\varepsilon \operatorname{Re}}{\left(\frac{\pi}{H_{1}}\right)^{2}+\left(\frac{\pi}{H_{2}}\right)^{2}+\frac{1}{\mathrm{Da}}} \ln \left\{\frac{\gamma C}{C-\left[\left(\frac{\pi}{H_{1}}\right)^{2}+\left(\frac{\pi}{H_{2}}\right)^{2}+\frac{1}{\mathrm{Da}}\right](\varepsilon \operatorname{Re})^{-1}}\right\}
$$

Calculations show that for large values of the number Da (rarefied skeleton) with increase in the number Re the unevenness of the velocity field in a porous heat exchanger is essentially inhomogeneous both in the hydrodynamic initial section and along the cross section with a quasi-parabolic profile (Fig. 2).

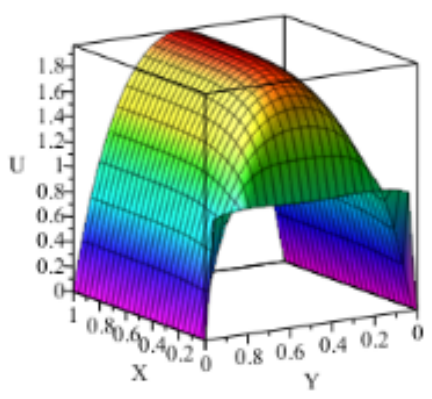

a

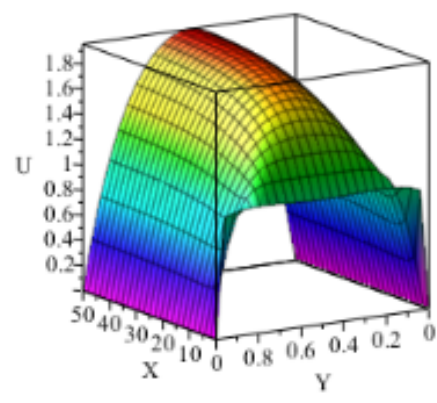

$\mathrm{b}$

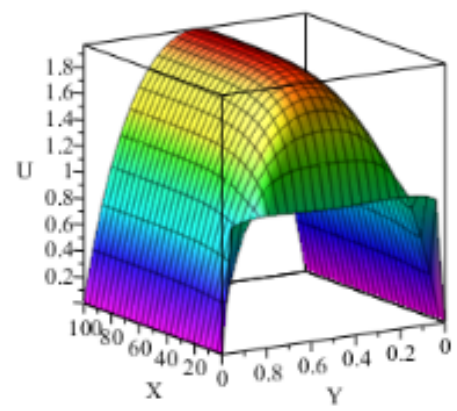

c

Fig. 2. A dimensionless velocity field in the cross section $z=0,5$ for $\mathrm{Da}=0,1, \eta=0,1$, $\varepsilon=0,4$ and different values of the numbers Re $: \mathrm{a}-10 ; \mathrm{b}-100 ; \mathrm{c}-1000$

The decrease in the value of the numbers Da significantly reduces the length of the hydrodynamic initial section, but the inhomogeneity of the velocity profile remains. Note that only for sufficiently small values $\mathrm{Da} \leq 10^{-4}$ there exists the homogeneous of the velocity field, and along the entire flow $U \approx 1$ (hydrodynamic regime of ideal displacement by heat carrier). The increase in the porosity of the skeleton under all other equal conditions leads to an increase in the length of the hydrodynamic initial section. The transition of the heat carrier flow to the flat case is observed for $\eta \leq 0,01$.

The hydraulic coefficient of resistance $\xi$ decreases with an increase in number Re, which agrees with the classical data. A sharp increase in the coefficient of resistance takes place in the region of small values of the numbers $\mathrm{Da}$, because the permeability of the skeleton of the heat exchanger porous medium decreases. Calculations show that the passage section in the form of a square is the most preferable from the point of view of the minimum pressure loss when moving the heat carrier in a porous heat exchanger, because in this case the wetted surface is minimal. Note that if there is no porous skeleton $(\varepsilon \rightarrow 1$, Da $\rightarrow \infty)$, then the resistance coefficient correlates with the value for a laminar flow of the Newtonian fluid in a rectangular channel for different $\eta[26]$. 
An analysis of the obtained relation for calculating the length of the initial segment shows that the length is directly proportional to $\mathrm{Re}$ and for $\varepsilon \rightarrow 1$, Da $\rightarrow \infty$ coincides with the data of [27].

\section{Heat Subproblem}

In practically important cases Da $\ll 10^{-5}$, therefore the system $(15)-(19)$ is essentially simplified, because $U \approx 1$. As for the hydrodynamic subproblem, we obtain a solution to the equations of the heat subproblem in the analytical form using the onesided integral Laplace transform of the variable $X$ and a consistent application of the final integral cosine transform with respect to the variables $Y$ and $Z$, respectively:

$$
\begin{aligned}
& T_{f}(X, Y, Z)=\frac{1}{H_{1} H_{2}}\left\{\frac{2 \Omega_{0}}{\operatorname{Re} \cdot \operatorname{Pr}} X+2 \sum_{m=1}^{\infty} \frac{b_{m}}{a_{m}}\left[\exp \left(a_{m} X\right)-1\right] \cos \left(p_{m} Y\right)+\right. \\
& \quad+2 \sum_{n=1}^{\infty} \frac{b_{n}}{a_{n}}\left[\exp \left(a_{n} X\right)-1\right] \cos \left(q_{n} Z\right)+ \\
& \left.+4 \sum_{m=1}^{\infty} \sum_{n=1}^{\infty} \frac{b_{m n}}{a_{m n}}\left[\exp \left(a_{m n} X\right)-1\right] \cos \left(q_{n} Z\right) \cos \left(p_{m} Y\right)\right\},
\end{aligned}
$$

where $p_{m}=m \pi / H_{1}, m=\overline{1, \infty}, q_{n}=n \pi / H_{2}, n=\overline{1, \infty}$,

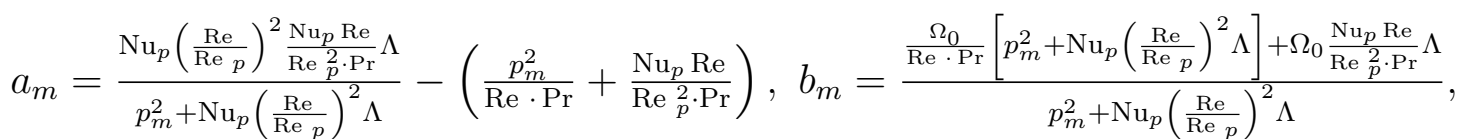

$$
\begin{aligned}
& a_{n}=\frac{\mathrm{Nu}_{p}\left(\frac{\mathrm{Re}}{\operatorname{Re} p}\right)^{2} \frac{\mathrm{Nu}_{p} \operatorname{Re}}{\operatorname{Re} \cdot \operatorname{Pr}} \Lambda}{q_{n}^{2}+\mathrm{Nu}_{p}\left(\frac{\operatorname{Re}}{\operatorname{Re} p}\right)^{2} \Lambda}-\left(\frac{q_{n}^{2}}{\operatorname{Re} \cdot \operatorname{Pr}}+\frac{\mathrm{Nu}_{p} \operatorname{Re}}{\operatorname{Re}{ }_{p}^{2} \cdot \operatorname{Pr}}\right), b_{n}=\frac{\frac{\Omega_{n}}{\operatorname{Re} \cdot \operatorname{Pr}}\left[q_{n}^{2}+\mathrm{Nu}_{p}\left(\frac{\operatorname{Re}}{\operatorname{Re} p}\right)^{2} \Lambda\right]+\Omega_{n} \frac{\mathrm{Nu}_{p} \operatorname{Re}}{\operatorname{Re} \frac{2}{2} \cdot \operatorname{Pr}} \Lambda}{q_{n}^{2}+\operatorname{Nu}_{p}\left(\frac{\operatorname{Re}}{\operatorname{Re} p}\right)^{2} \Lambda}, \\
& a_{m n}=\frac{\mathrm{Nu}_{p}\left(\frac{\mathrm{Re}}{\operatorname{Re} p}\right)^{2} \frac{\mathrm{Nu}_{p} \operatorname{Re}}{\operatorname{Re} 2 \cdot \operatorname{Pr}} \Lambda}{p_{m}^{2}+q_{n}^{2}+\mathrm{Nu}_{p}\left(\frac{\mathrm{Re}}{\operatorname{Re} p}\right)^{2} \Lambda}-\left(\frac{p_{m}^{2}}{\operatorname{Re} \cdot \operatorname{Pr}}+\frac{q_{n}^{2}}{\operatorname{Re} \cdot \operatorname{Pr}}+\frac{\mathrm{Nu}_{p} \operatorname{Re}}{\operatorname{Re}{ }_{p}^{2} \cdot \operatorname{Pr}}\right), \\
& b_{m n}=\frac{\frac{\Omega_{n}}{\operatorname{Re} \cdot \operatorname{Pr}}\left[p_{m}^{2}+q_{n}^{2}+\mathrm{Nu}_{p}\left(\frac{\mathrm{Re}}{\operatorname{Re} p}\right)^{2} \Lambda\right]+\Omega_{n} \frac{\mathrm{Nu}_{p} \operatorname{Re}}{\operatorname{Re} \frac{2}{2} \cdot \operatorname{Pr}} \Lambda}{p_{m}^{2}+q_{n}^{2}+\mathrm{Nu}_{p}\left(\frac{\operatorname{Re}}{\operatorname{Re} p}\right)^{2} \Lambda} \\
& \Omega_{n}=\left\{\begin{array}{c}
\frac{2}{\pi} \sum_{k=1}^{\infty} \frac{1}{k}\left[1-(-1)^{k}\right]\left\langle\frac{H_{2}}{2 \pi(k-n)}\{1-\cos [\pi(k-n)]\}+\right. \\
\left.+\frac{H_{2}}{2 \pi(k+n)}\{1-\cos [\pi(k+n)]\}\right\rangle, \text { if } n \neq k, \\
0, \quad \text { if } k=n .
\end{array}\right. \\
& T_{s}(X, Y, Z)=\frac{1}{H_{1} H_{2}}\left\{\frac{\Omega_{0}}{\operatorname{Nu}_{p}\left(\frac{\operatorname{Re}}{\operatorname{Re}_{p}}\right)^{2} \Lambda}+\frac{2 \Omega_{0} X}{\operatorname{Re} \cdot \operatorname{Pr} \cdot \Lambda}+\right. \\
& +2 \sum_{m=1}^{\infty} f_{m}\left[\left(1-\frac{c_{m}}{d_{m}}\right) \exp \left(-d_{m} X\right)+\frac{c_{m}}{d_{m}}\right] \cos \left(p_{m} Y\right)+ \\
& +2 \sum_{n=1}^{\infty} f_{n}\left[\left(1-\frac{c_{n}}{d_{n}}\right) \exp \left(-d_{n} X\right)+\frac{c_{n}}{d_{n}}\right] \cos \left(q_{n} Z\right)+ \\
& \left.+4 \sum_{m=1}^{\infty} \sum_{n=1}^{\infty} f_{m n}\left[\left(1-\frac{c_{m n}}{d_{m n}}\right) \exp \left(-d_{m n} X\right)+\frac{c_{m n}}{d_{m n}}\right] \cos \left(q_{n} Z\right) \cos \left(p_{m} Y\right)\right\} \text {, }
\end{aligned}
$$


where

$$
\begin{aligned}
& c_{m}=\frac{p_{m}^{2}}{\operatorname{Re} \cdot \operatorname{Pr}}+\frac{\mathrm{Nu}_{p} \operatorname{Re}}{\operatorname{Re}_{p}^{2} \cdot \operatorname{Pr}}+\frac{\mathrm{Nu}_{p}}{\operatorname{Re} \cdot \operatorname{Pr}}\left(\frac{\mathrm{Re}}{\operatorname{Re} p}\right)^{2}, \\
& d_{m}=\frac{p_{m}^{2}}{\operatorname{Re} \cdot \operatorname{Pr}}+\frac{\mathrm{Nu}_{p} \operatorname{Re}}{\operatorname{Re}{ }_{p}^{2} \cdot \operatorname{Pr}}-\mathrm{Nu}_{p}\left(\frac{\operatorname{Re}}{\operatorname{Re}_{p}}\right)^{2} \frac{\mathrm{Nu}_{p} \operatorname{Re}}{\operatorname{Re}_{p}^{2} \cdot \operatorname{Pr}} \Lambda /\left[p_{m}^{2}+\mathrm{Nu}_{p}\left(\frac{\operatorname{Re}}{\operatorname{Re}_{p}}\right)^{2} \Lambda\right], \\
& f_{m}=\Omega_{0} /\left[p_{m}^{2}+\mathrm{Nu}_{p}\left(\frac{\operatorname{Re}}{\operatorname{Re} p}\right)^{2} \Lambda\right], c_{n}=\frac{q_{n}^{2}}{\operatorname{Re} \cdot \operatorname{Pr}}+\frac{\mathrm{Nu}_{p} \operatorname{Re}}{\operatorname{Re}{ }_{p}^{2} \cdot \operatorname{Pr}}+\frac{\mathrm{Nu}_{p}}{\operatorname{Re} \cdot \operatorname{Pr}}\left(\frac{\operatorname{Re}}{\operatorname{Re} p}\right)^{2}, \\
& d_{n}=\frac{q_{n}^{2}}{\operatorname{Re} \cdot \operatorname{Pr}}+\frac{\mathrm{Nu}_{p} \operatorname{Re}}{\operatorname{Re}{ }_{p}^{2} \cdot \operatorname{Pr}}-\mathrm{Nu}_{p}\left(\frac{\operatorname{Re}}{\operatorname{Re}_{p}}\right)^{2} \frac{\mathrm{Nu}_{p} \operatorname{Re}}{\operatorname{Re}_{p}^{2} \cdot \operatorname{Pr}} \Lambda /\left[q_{n}^{2}+\mathrm{Nu}_{p}\left(\frac{\mathrm{Re}}{\operatorname{Re}_{p}}\right)^{2} \Lambda\right] \\
& f_{n}=\Omega_{n} /\left[q_{n}^{2}+\mathrm{Nu}_{p}\left(\frac{\operatorname{Re}}{\operatorname{Re} p}\right)^{2} \Lambda\right], c_{m n}=\frac{p_{m}^{2}}{\operatorname{Re} \cdot \operatorname{Pr}}+\frac{q_{n}^{2}}{\operatorname{Re} \cdot \operatorname{Pr}}+\frac{\mathrm{Nu}_{p} \operatorname{Re}}{\operatorname{Re}{ }_{p}^{2} \cdot \operatorname{Pr}}+\frac{\mathrm{Nu}_{p}}{\operatorname{Re} \cdot \operatorname{Pr}}\left(\frac{\mathrm{Re}}{\operatorname{Re} p}\right)^{2}, \\
& d_{m n}=\frac{p_{m}^{2}}{\operatorname{Re} \cdot \operatorname{Pr}}+\frac{q_{n}^{2}}{\operatorname{Re} \cdot \operatorname{Pr}}+\frac{\mathrm{Nu}_{p} \operatorname{Re}}{\operatorname{Re}_{p}^{2} \cdot \operatorname{Pr}}-\mathrm{Nu}_{p}\left(\frac{\operatorname{Re}}{\operatorname{Re} p}\right)^{2} \frac{\mathrm{Nu}_{p} \operatorname{Re}}{\operatorname{Re}_{p}^{2} \cdot \operatorname{Pr}} \Lambda /\left[p_{m}^{2}+q_{n}^{2}+\mathrm{Nu}_{p}\left(\frac{\operatorname{Re}}{\operatorname{Re}_{p}}\right)^{2} \Lambda\right] \text {, } \\
& f_{m n}=\Omega_{n} /\left[p_{m}^{2}+q_{n}^{2}+\mathrm{Nu}_{p}\left(\frac{\operatorname{Re}_{p}}{\operatorname{Re}_{p}}\right)^{2} \Lambda\right] .
\end{aligned}
$$

Note that the porosity in the explicit form does not enter into the solution to the heat subproblem (24), (25), but is contained in the defining dimensionless numbers. Therefore, we represent the defining parameters as follows:

$$
\begin{gathered}
\operatorname{Re}=\operatorname{Re}^{0} / \varepsilon^{2}, \operatorname{Re}_{p}=\operatorname{Re}_{p}^{0} /[6(1-\varepsilon)], \operatorname{Pr}=\varepsilon \operatorname{Pr}^{0} /\left(\varepsilon+0,3 \operatorname{Pr}^{0} \operatorname{Re}_{p}^{0}\right), \\
\operatorname{Nu}_{p}=\left(2+1,1 \operatorname{Pr}^{0^{1 / 3}} \operatorname{Re}_{p}^{3 / 5}\right) /\left(\varepsilon+0,3 \operatorname{Pr}^{0} \operatorname{Re}_{p}^{0}\right),
\end{gathered}
$$

where $\operatorname{Re}^{0}=\rho_{f} u_{0} d_{h} / \mu_{f}, \operatorname{Re}_{p}^{0}=\rho_{f} u_{0} d_{p} / \mu_{f}$.

Calculation analysis of the heat subproblem in Fig. 3 shows that the small Reynolds numbers equalize the temperature of the heat carrier and the porous skeleton due to the greater heat conductivity of the porous matrix material. However, in this case the efficiency of the heat transfer is very low, and the increase in the velocity of the heat carrier sharply increases the efficiency. But at the same time, a significant inhomogeneity of the temperature field takes place. And as expected, the temperature of the heat carrier near the cooled surface is much higher, therefore the surface overheats. This situation can cause a phase transition (boil of the cooler). An increase in the local Reynolds number, that is an increase in the permeability with a constant velocity of the heat carrier at the input of the heat exchanger, leads to a deterioration in the thermal indices.

In order to increase the cooling effect of the surface extracting heat and at the same time reduce a heat load on the heat carrier, we can variate the Prandtl numbers such that to increase the numbers.

Note that the parameter $\Lambda$ characterizes the ratio of effective thermal conductivities of the heat carrier and a material of the porous structure. A decrease in the parameter $\Lambda$ leads to an increase in the heat dissipation, and the increase in porosity worsens the entire spectrum of thermal indices of the heat exchanger.

It is established that an increase in the ratio of the height to the width of the flow section, with all other equal conditions, leads to a more intensive cooling of the surface extracting heat (Fig. 4). In this case, there is an analogy with the functioning of the cooling edge for the usual method to intensify the heat transfer, i.e. there exists an optimal ratio of the height and width of flow section of the porous heat exchanger, which provides the maximum heat dissipation from the cooled surface. 

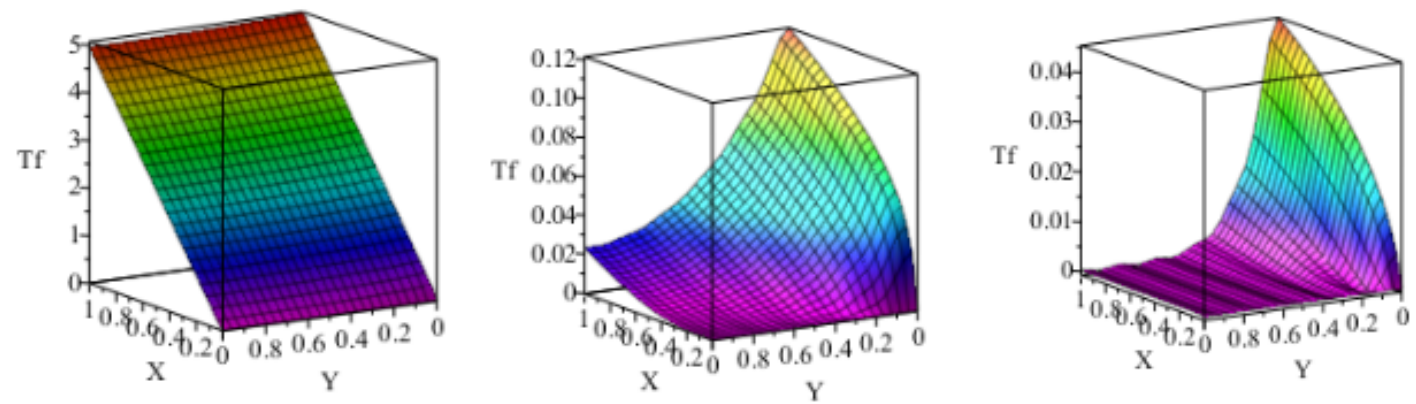

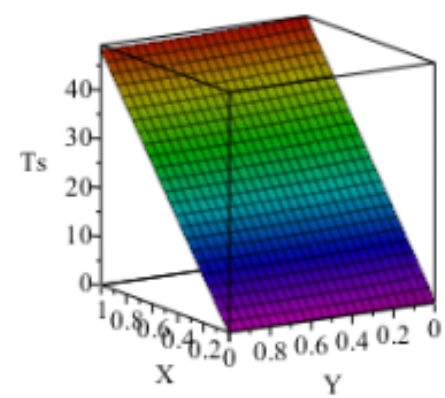

a

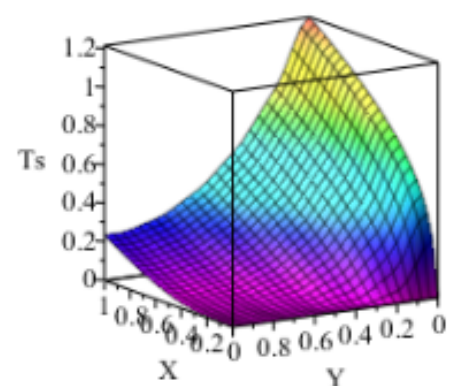

$\mathrm{b}$

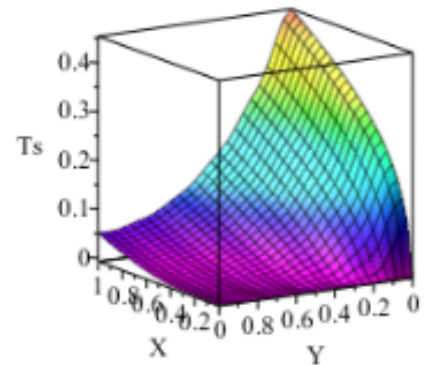

$\mathrm{c}$

Fig. 3. Dimensionless fields of heat carrier temperatures and matrix of a porous layer in the plane $z=0,5$ for $\varepsilon=0,2, \operatorname{Re}_{p}^{0}=100, \operatorname{Pr}^{0}=0,002, \Lambda=0,1, \eta=1$ and for different Re: $a-10 ; b-1000 ; c-10000$

Therefore, we analyze the calculation of temperature fields of the heat carrier and the matrix of the porous medium in the heat exchanger. The results of the analysis confirm that the mathematical model is qualitative, adequate, correct and agrees with the modern concepts of the heat exchange in the porous media. Estimation of the local Nusselt number for a porous heat exchanger

$$
N u(X)=\left[\bar{T}_{f}(X, 0)-\left\langle T_{f}(X)\right\rangle\right]^{-1},
$$

where $\bar{T}_{f}(X, 0)=\frac{1}{H_{2}} \int_{0}^{H_{2}} T(X, 0, Z) d Z,\left\langle T_{f}(X)\right\rangle=\frac{1}{H_{1} \cdot H_{2}} \int_{0}^{H_{1}} \int_{0}^{H_{2}} T_{f}(X, Y, Z) d Y d Z$ is constructed by the following considerations. The averaging of the heat subproblem (15) (19) for $U=1$ leads the subproblem to the differential-algebraic system:

$$
\begin{aligned}
& \frac{d\left\langle T_{f}(X)\right\rangle}{d X}=\frac{1}{\operatorname{Re} \cdot \operatorname{Pr}}+\frac{\mathrm{Nu}_{p} \operatorname{Re}}{\operatorname{Re}{ }_{p}^{2} \operatorname{Pr}}\left[\Lambda\left\langle T_{s}(X)\right\rangle-\left\langle T_{f}(X)\right\rangle\right], \\
& \operatorname{Nu}_{p}\left(\frac{\operatorname{Re}}{\operatorname{Re}_{p}}\right)^{2}\left[\Lambda\left\langle T_{s}(X)\right\rangle-\left\langle T_{f}(X)\right\rangle\right]=1,\left\langle T_{f}(0)\right\rangle=0,
\end{aligned}
$$

and the solution of the system is the following:

$$
\begin{gathered}
\left\langle T_{f}(X)\right\rangle=\frac{1}{\operatorname{Pr}}\left[\frac{1}{\operatorname{Re}}+\mathrm{Nu}_{p}^{2}\left(\frac{\operatorname{Re}}{\operatorname{Re}_{p}}\right)^{3}\right] X, \\
\left\langle T_{s}(X)\right\rangle=\frac{1}{\Lambda}\left\{\mathrm{Nu}_{p}\left(\frac{\operatorname{Re}}{\operatorname{Re}_{p}}\right)^{2}+\frac{1}{\operatorname{Pr}}\left[\frac{1}{\operatorname{Re}}+\mathrm{Nu}_{p}^{2}\left(\frac{\operatorname{Re}}{\operatorname{Re}_{p}}\right)^{3}\right] X\right\} .
\end{gathered}
$$



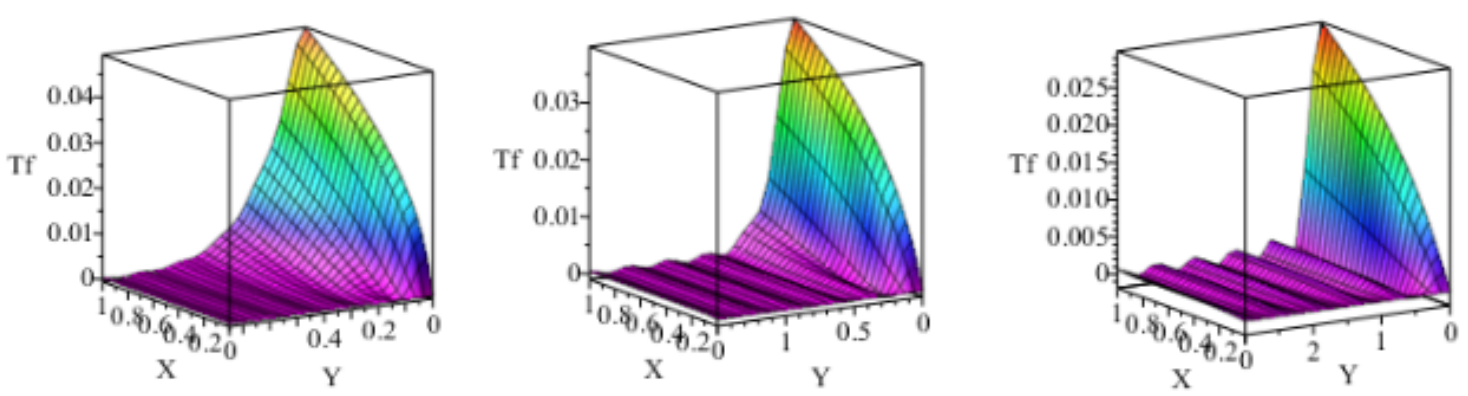

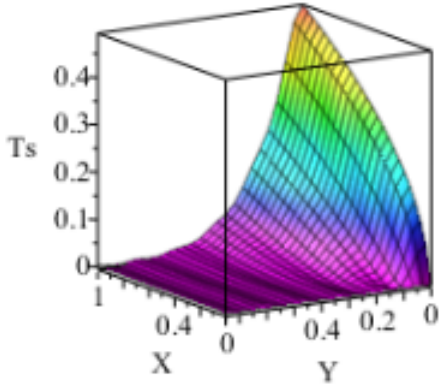

a

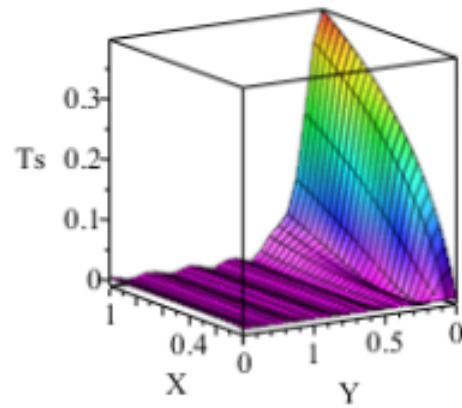

$\mathrm{b}$

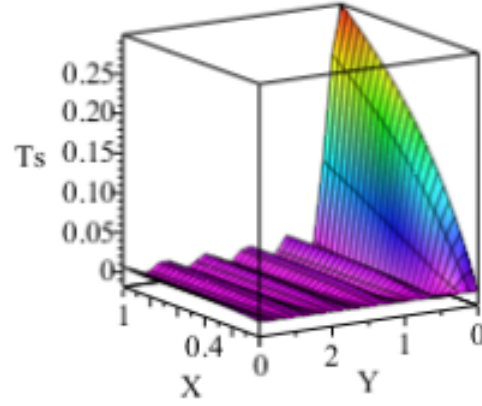

$\mathrm{c}$

Fig. 4. Dimensionless fields of heat carrier temperatures and matrices of a porous layer in the plane $z=0,5$ for $\varepsilon=0,2, \operatorname{Re}^{0}=10000, \operatorname{Re}_{p}^{0}=100, \operatorname{Pr}^{0}=0,002, \Lambda=0,1$ and for different $\eta: \mathrm{a}-0,5 ; \mathrm{b}-2 ; \mathrm{c}-5$

Note that the axial change in temperatures of the heat carrier and matrix of the porous medium is linear.

The result of the averaging of the heat subproblem only for the variable $Z$ is analogous to the flat case, the solution of which was obtained in [28]. In this solution suppose that the height of the flat channel is equal to the hydraulic diameter of the cross section of the porosity of the 3-D heat exchanger, then

$$
\bar{T}_{f}(X, 0)=\frac{2}{\operatorname{Re} \cdot \operatorname{Pr} \cdot a^{f}}\left[1-\exp \left(a^{f} X\right)\right]+2 \sum_{k=1}^{\infty} \frac{c_{k}^{f}}{b_{k}^{f}}\left[1-\exp \left(b_{k}^{f} X\right)\right],
$$

where

$$
\begin{gathered}
a^{f}=\frac{\mathrm{Nu}_{p} \operatorname{Re}}{\operatorname{Re} p \operatorname{Pr}}\left(\frac{1}{\operatorname{Re} p}-1\right), \\
b_{k}=\frac{\pi^{2} k^{2}}{\operatorname{Re} \cdot \operatorname{Pr}}+\frac{\mathrm{Nu}_{p} \operatorname{Re}}{\operatorname{Re}{ }_{p}^{2} \operatorname{Pr}}-\frac{\mathrm{Nu}_{p}^{2} \operatorname{Re}^{3}}{\operatorname{Re}_{p}^{4} \operatorname{Pr}} \Lambda /\left[\pi^{2} k^{2}+\mathrm{Nu}_{p}\left(\frac{\mathrm{Re}}{\operatorname{Re}_{p}}\right)^{2} \Lambda\right], \\
c_{k}^{f}=\left(\frac{2 \mathrm{Nu}_{p} \operatorname{Re}}{\operatorname{Re}_{p}^{2} \operatorname{Pr}} \Lambda+\frac{\pi k^{2}}{\operatorname{Re} \cdot \operatorname{Pr}}\right) /\left[\pi^{2} k^{2}+\mathrm{Nu}_{p}\left(\frac{\operatorname{Re}}{\operatorname{Re}_{p}}\right)^{2} \Lambda\right] .
\end{gathered}
$$

The calculations of the local Nusselt number for a porous heat exchanger according to the formula (26) with taking into account the ratio (27) and (28) prove (Fig. 5) that together with the increase of the porosity its meaning decreases with simultenuous decrease of the heat initial section because of the deceleration of the heat carrier in the matrix of the skeleton. 


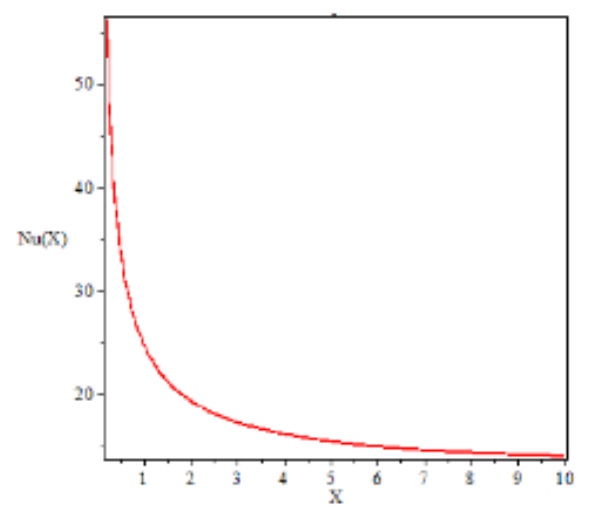

a

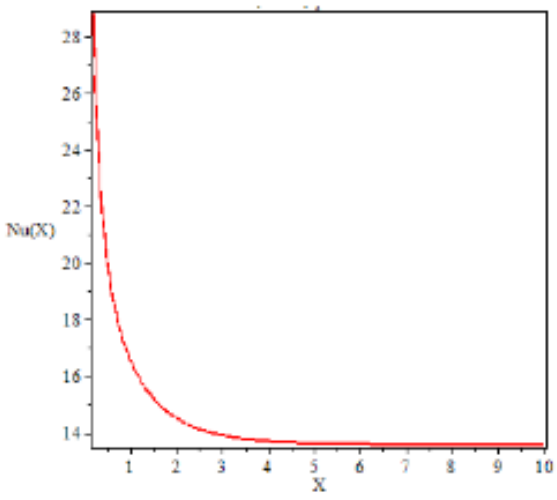

$\mathrm{b}$

Fig. 5. The local Nusselt number for a porous heat exchanger for $\operatorname{Re}^{0}=10000 ; \operatorname{Re}_{p}^{0}=100$; $\operatorname{Pr}^{0}=0,002 ; \Lambda=0,1, \eta=1$ and different values of porosity $\varepsilon: \mathrm{a}-0,2 ; \mathrm{b}-0,4$

\section{Conclusion}

The presented mathematical model gives a wide range of different heat-hydraulic characteristics of porous heat exchangers and can be considered as universal tool to develop a new one and to choose the rational modes of functioning of the existing heat exchange equipment.

Acknowledgements. The paper was supported by the Ministry of Education and Science of the Russian Federation under the Federal Target Program (Agreement № 14.577.21.0202, the unique identifier is RFMEFI57715X0202).

\section{References}

1. Delavar M.A., Azimi M.I. Using Porous for Heat Transfer Enhancement in Heat Exchangers: Review. Journal of Engineering Science and Technology Review, 2013, vol. 6, no. 1, pp. 14-16.

2. Bayomy A.M., Saghir M.Z. Heat Transfer Characteristics of Aluminum Metal Foam Subjected to a Pulsating Steady Water Flow: Experimental and Numerical Approach. International Journal of Heat and Mass Transfer, 2016, vol. 97, pp. 318-336. DOI: 10.1016/j.ijheatmasstransfer.2016.02.009

3. Emerging Technologies and Techniques in Porous Media. Eds: D. Ingham, A. Bejan, E. Mamut, I. Pop. Springer Netherlands, 2004. 507 p. DOI: 10.1007/978-94-007-0971-3

4. Hung T.C., Hung Y.S., Yan W.M. Design of Porous-Microchannel Heat Sinks with Different Porous Configurations. International Journal of Materials, Mechanics and Manufacturing, 2016, vol. 4, no. 2, pp. 89-94. DOI: 10.7763/IJMMM.2016.V4.231

5. Vafai K. Handbook of Porous Media. N.Y., CRC Press Taylor \& Francis Group, 2005. 742 p.

6. Hooman K., Merrikh A.A. Analytical Solution of Forced Convection in a Duct of Rectangular Cross Section Saturated by a Porous Medium. Journal of Heat Transfer, 2006, vol. 128, no 6, pp. 596-600. DOI: $10.1115 / 1.2188510$

7. Hooman K., Gurgenci H., Merrikh A.A. Heat Transfer and Entropy Generation Optimization of Forced Convection in Porous-Saturated Ducts of Rectangular Cross-Section. 
International Journal of Heat and Mass Transfer, 2007, vol. 50, no. 10, pp. 2051-2059. DOI: $10.1016 /$ j.ijheatmasstransfer.2006.11.015

8. Kurtbas I., Celik N. Experimental Investigation of Forced and Mixed Convection Heat Transfer in a Foam-Filled Horizontal Rectangular Channel. International Journal of Heat and Mass Transfer, 2009, vol. 52, no. 9, pp. 1313-1325. DOI: 10.1016/j.ijheatmasstransfer.2008.07.050

9. Chen G.M., Tso C.P. A Two-Equation Model for Thermally Developing Forced Convection in Porous Medium with Viscous Dissipation. International Journal of Heat and Mass Transfer, 2011, vol. 54, no. 25-26, pp. 5406-5414. DOI: 10.1016/j.ijheatmasstransfer.2011.08.002

10. Teamah M.A., El-Maghlany W.M., Dawood M.M.K. Numerical Simulation of Laminar Forced Convection in Horizontal Pipe Partially or Completely Filled with Porous Material. International Journal of Thermal Science, 2011, vol. 50, no. 8, pp. 1512-1522. DOI: 10.1016/j.ijthermalsci.2011.03.003

11. Nield D.A., Bejan A. Convection in Porous Media. N.Y., Springer, 2006. 654 p.

12. Lu W., Zhao C.Y., Tassen S.A. Thermal Analysis on Metal-Foam Filled Heat Exchangers. International Journal Heat Mass Transfer, 2006, vol. 49, no. 11, pp. 2751-2770. DOI: 10.1016/j.ijheatmasstransfer.2005.12.012

13. Bear J., Bachmat Y. Introduction to Modeling of Transport Phenomena in Porous Media. Netherlands, Kluwer Academic Publishers, 1991. 553 p.

14. Hsu C.T., Cheng P. Thermal Dispersion in a Porous Medium. International Journal of Heat and Mass Transfer, 1990, vol. 33, no. 8, pp. 1587-1597. DOI: 10.1016/0017-9310(90)90015-M

15. Beji H., Gobin D. Influence of Thermal Dispersion on Natural-Convection Heat-Transfer in Porous-Media. Numerical of Heat Tranfer, Part A, 1992, vol. 22, pp. 487-500. DOI: $10.1080 / 10407789208944779$

16. Gamal A.A., Furmanski P. Problems of Modeling Flow and Heat Transfer in Porous Media. Biuletyn Instytutu Techniki Cieplnej Politechniki Warszawskiej, 1997, no. 85, pp. 55-88.

17. Amiri A., Vafai K. Analysis of Dispersion Effects and Non Thermal Equilibrium, Non-Darsian Vairiable Porosity Incompressible Flow Through Porous Media. International Journal of Heat and Mass Transfer, 1994, vol. 37, no. 6, pp. 939-954. DOI: 10.1016/0017-9310(94)90219-4

18. Popov I.A. Gidrodinamika i teploobmen v poristykh teploobmennykh elementakh i apparatakh [Hydrodynamics and Heat Transfer in Porous Heat Exchange Elements and Devices]. Kazan, Tsentr innovatsionnykh tekhnologiy, 2007. 240 p. [Попов, И.А. Гидродинамика и теплообмен в пористых теплообменных элементах и аппаратах / И.А. Попов. - Казань: Центр информационных технологий, 2007. - 240 с.]

19. Transport Phenomena in Porous Media. III. Eds. D.B. Ingham, I. Pop. Oxford, Elsevier Ltd., 2005. 476 p.

20. Ezzati R., Rassoulinejad S.M. Application of Homotopy Perturbation Method for Solving Brinkman Momentum Equation for Fully Developed Forced Convection in a Porous Saturated Channel. Mathematical Science, 2011, vol. 5, no. 2, pp. 111-123.

21. Izadpanah M.R., Muller-Steinhagen H., Jamialahmadi M. Experimental and Theoretical Studies of Convective Heat Transfer in a Cylindrical Porous Medium. International Journal of Heat and Fluid Flow, 1998, vol. 19, pp. 629-635. DOI: 10.1016/S0142-727X(98)10035-8

22. Slyezkin N.A. Dinamika vyazkoy neszhimaemoy zhidkosti [The Viscous Incompressible Fluid Dynamics]. Moscow, Gosudarstvennoe izdatel'stvo tekhniko-teoreticheskoy literatury, 1955. 579 р. [Слезкин, Н.А. Динамика вязкой несжимаемой жидкости / Н.А. Слезкин. - М.: Гос. изд-во технико-теоретической лит-ры, 1955. - 579 с.] 
23. Dotsch G. Anleitung zum praktischen gebrauch der Laplace-transformation und der z-transformation. Wien, 1967. (in Deutch)

24. Sneddon I.N. Fourier Transforms. N.Y., McGraw-Hill, 1951. 542 p.

25. Bird R.B., Stewart W.E., Lightfoot E.N. Transport Phenomena. N.Y., London, Journal Wiley \& Sons, 2002. 914 p.

26. Ozlsik M.N. Heat Transfer: A Basic Approach. Singapore, McGraw - Hill Book Company, 1985. $576 \mathrm{p}$

27. Lin J.N., Chron F.C., Tzeng P.Y. Theoretical Prediction of the Outset of Thermal Instability in the Thermal Entrance Region of Horizontal Rectangular Channels. International Journal of Heat and Fluid Flow, 1991, vol. 12, no. 3, pp. 218-224. DOI: 10.1016/0142-727X(91)90055-Z

28. Ryazhskih V.I., Konovalov D.A., Slyusarev M.I., Drozdov I.G. Analysis of Mathematical Model Heat Removal from the Flat Surface by the Laminar Moving Refrigerant through Conjugation Porous Medium. Bulletin of the South Ural State University. Series: Mathematical Modelling, Programming and Computer Software, 2016, vol. 9, no. 3, pp. 68-81. DOI: 10.14529/mmp160306 [Ряжских, В.И. Анализ математической модели теплосъема с плоской поверхности ламинарно движущимся хладагентом через сопряженную пористую среду / В.И. Ряжских, Д.А. Коновалов, М.И. Слюсарев, И.Г. Дроздов // Вестник ЮУрГУ. Серия: Математическое моделирование и программирование. - 2016. - Т. 9, № 3. - C. $68-81$.]

Received May 5, 2017

УДК 621.1.016.4(03)

DOI: $10.14529 / \mathrm{mmp} 170304$

\title{
АНАЛИТИЧЕСКОЕ РЕШЕНИЕ ЗАДАЧИ КОНВЕКТИВНОГО ТЕПЛОПЕРЕНОСА В ПОРИСТОМ ПРЯМОУГОЛЬНОМ КАНАЛЕ ПРИ ТЕРМИЧЕСКИХ ГРАНИЧНЫХ УСЛОВИЯХ ВТОРОГО РОДА
}

\author{
В.И. Ряюских ${ }^{1}$, Д.А. Коновалов ${ }^{1}$ А.В. Ряжских ${ }^{1}$, А.А. Богер ${ }^{2}$, \\ C.В. Дахин ${ }^{1}$ \\ ${ }^{1}$ Воронежский государственный технический университет, г. Воронеж \\ ${ }^{2}$ Военный учебно-научный центр Военно-воздушных сил «Военно-воздушная \\ академия имени профессора Н.Е. Жуковского и Ю.А. Гагарина», г. Воронеж
}

В трехмерной постановке рассмотрено уравнение Бринкмана совместно с уравнением гетерогенного теплопереноса для однонаправленного течения ньютоновской жидкости при ламинарном режиме через горизонтальный пористый канал постоянного прямоугольного поперечного сечения с известными термическими потоками на границе и малыми значениями чисел Дарси. В силу линейности сформулированной системы уравнений модели получено ее аналитическое решение с использованием интегральных преобразований Лапласа и Фурье. Найденное решение позволило оценить длину входного гидродинамического участка, коэффициент гидравлического сопротивления и локальные числа Нуссельта. Полученные результаты для гидродинамической подзадачи при большой пористости и тепловой подзадачи при стационарном поле температур согласуются с классическим данными.

Ключевые слова: пористые среды; конвективный теплообмен; прямоугольный канал; коэффициент гидравлического сопротивления; начальный гидродинамический участок. 
Виктор Иванович Ряжских, доктор технических наук, профессор, кафедра «Прикладная математика и механика», Воронежский государственный технический университет (г. Воронеж, Российская Федерация), ryazhskih_vi@mail.ru.

Дмитрий Альбертович Коновалов, кандидат технических наук, доцент, кафедра «Теоретическая и промышленная теплоэнергетика», Воронежский государственный технический университет (г. Воронеж, Российская Федерация), dmikonovalov@yandex.ru.

Александр Викторович Ряжских, кандидат физико-математических наук, доцент, кафедра «Прикладная математика и механика», Воронежский государственный технический университет (г. Воронеж, Российская Федерация), ryazhskihav@bk.ru.

Андрей Александрович Богер, кандидат технических наук, доцент, кафедра «Математика», Военный учебно-научный центр Военно-воздушных сил «Военновоздушная академия имени профессора Н.Е. Жуковского и Ю.А. Гагарина» (г. Воронеж, Российская Федерация), a-boger@yandex.ru.

Сергей Викторович Дахин, кандидат технических наук, доцент, кафедра «Теоретическая и промышленная теплоэнергетика», Воронежский государственный технический университет (г. Воронеж, Российская Федерация), secretaryd21203705@yandex.ru.

Поступила в редакцию 5 мая 2017 г. 